\title{
Epidemiology of Cryptosporidium sp. infection among free-range and intensive farm birds in Akure South LGA, Ondo State, Nigeria
}

\author{
Akinbode Ayekooto Olonisakin * (D) and Titus Adeniyi Olusi
}

\begin{abstract}
Background: Cryptosporidium spp. is an intracellular zoonotic protozoan parasite that causes cryptosporidiosis, a diarrhoeal disease of humans and domestic animals. Transmission of Cryptosporidiosis to humans and other animals is by ingestion of oocysts of the parasite and as low as ten oocysts can cause clinical infections in otherwise healthy persons. The aim of this study is to investigate the prevalence of Cryptosporidiosis and compare the rate of infection between free range bird and poultry bird reared in Akure South LGA, Ondo State, Nigeria.

Result: The overall prevalence of Cryptosporidium reported in this study was $11.9 \%$. Free-range birds show a higher prevalence rate $13.2 \%$ of Cryptosporidium oocysts than $10.9 \%$ in poultry birds. Aule recorded the highest prevalence of Cryptosporidium oocysts infection (16.1\%) followed by Ipinsa (12.2\%), Onigari (10\%), and FUTA (8.1\%). The highest prevalence 15.9\% was recorded in broilers, while turkey showed no infection (0\%) by Cryptosporidium. Semi-intensive system of farming was showed to be more susceptible to Cryptosporidium oocysts infection at $13.3 \%$ followed by the $12.6 \%, 10.3 \%$ in deep litter and battery cage. The female birds recorded higher Cryptosporidium oocysts infection (12.2\%) than the male (11.6\%).
\end{abstract}

Conclusion: The study established the presence of Cryptosporidium oocysts infection among studied birds in Akure South LG of Ondo State, Nigeria.

Keywords: Epidemiology, Cryptosporidium oocysts, Infection, Free-range, Poultry, Birds

\section{Background}

Cryptosporidiosis is an emerging zoonotic disease, resulting in intestinal and extraintestinal disorders in both humans and animals (Fayer et al. 2000). Transmission of Cryptosporidium oocysts infections is through multiple routes. Infections may be transmitted through person to person, which is particularly important in daycare settings with children; by direct contact with infected animal or via faecal-oral route or by ingestion of oocysts contaminated water and food (Khan et al. 2004). Transmission of Cryptosporidiosis to humans and other animals is by ingestion of oocysts of the parasite (Fayer

\footnotetext{
*Correspondence: olonisakin.akinbode@gmail.com

olonisakinbio116459@futa.edu.ng

Federal University of Technology Akure, Akure, Ondo State, Nigeria
}

2010) and as low as ten oocysts can cause clinical infections in otherwise healthy persons (DuPont et al. 1995). These oocysts are resistant to most common disinfectants and are not readily killed by routine chlorination of water (LeChevallier et al. 1991). Cryptosporidium can infect more than 30 avian species. However, three different Cryptosporidium species (C. parvum, C. meleagridis, and C. galli) were considered the major pathogens of birds. The occurrence of animal Cryptosporidium spp. in humans indicates that humans are constantly at risk of contracting cryptosporidiosis from these reservoir hosts. Cryptosporidium infections in humans account for up to $6 \%$ of all diarrhoea cases in immune competent persons and $24 \%$ of persons with both HIV and diarrhoea worldwide (Bialek et al. 2002; UNICEF 2007). Cryptosporidium was included in the World Health Organization's 
Neglected Diseases Initiative in order to enhance knowledge on the epidemiology and host-parasite interactions especially through molecular techniques (Savioli et al. 2006). In poultry houses, shared water source is an effective means of sharing the oocysts among birds and hence infecting a large number. Cryptosporidium infections continue to be a significant health problem in both developed and developing countries (Harp 2003), where it is recognized as an important cause of diarrhoea in both immunocompromised and immunocompetent people (Kjos et al. 2005). They are different free range and poultry farms that serves as major producers of birds and eggs for public consumption in the study area Akure. Although the prevalence of Cryptosporidium has been studied in various parts of Nigeria, there is paucity of information on the epidemiology and comparison of Cryptosporidium infection especially in this part of the country. Thus, the aim of this study is to investigate and compare Cryptosporidium infections among free range and intensive chicken and turkey farms reared in the study area.

\section{Method}

Study areas

The study was conducted in four locations within Akure South Local Government Area in Ondo State, Nigeria (Fig. 1) and with a total population of 486,300 . The city covers an estimated area of $331 \mathrm{~km}^{2}$ and is located at 7.2050'N latitude and 5.1877E longitude.

\section{Study design}

This was a cross-sectional study. A total of 437 birds including 247 from farms and 190 local breeds from free range (Tables 1 and 3) reared in Aule, Ipinsa, FUTA, and Onigari (Table 2) were sampled for this study. Furthermore, samples were collected from three (3) species of birds present in the poultries selected. Sampling sites were conveniently selected at random.

\section{Laboratory analysis of samples}

Laboratory method, namely Modified Ziehl Neelsen, is used to diagnose Cryptosporidium infection.

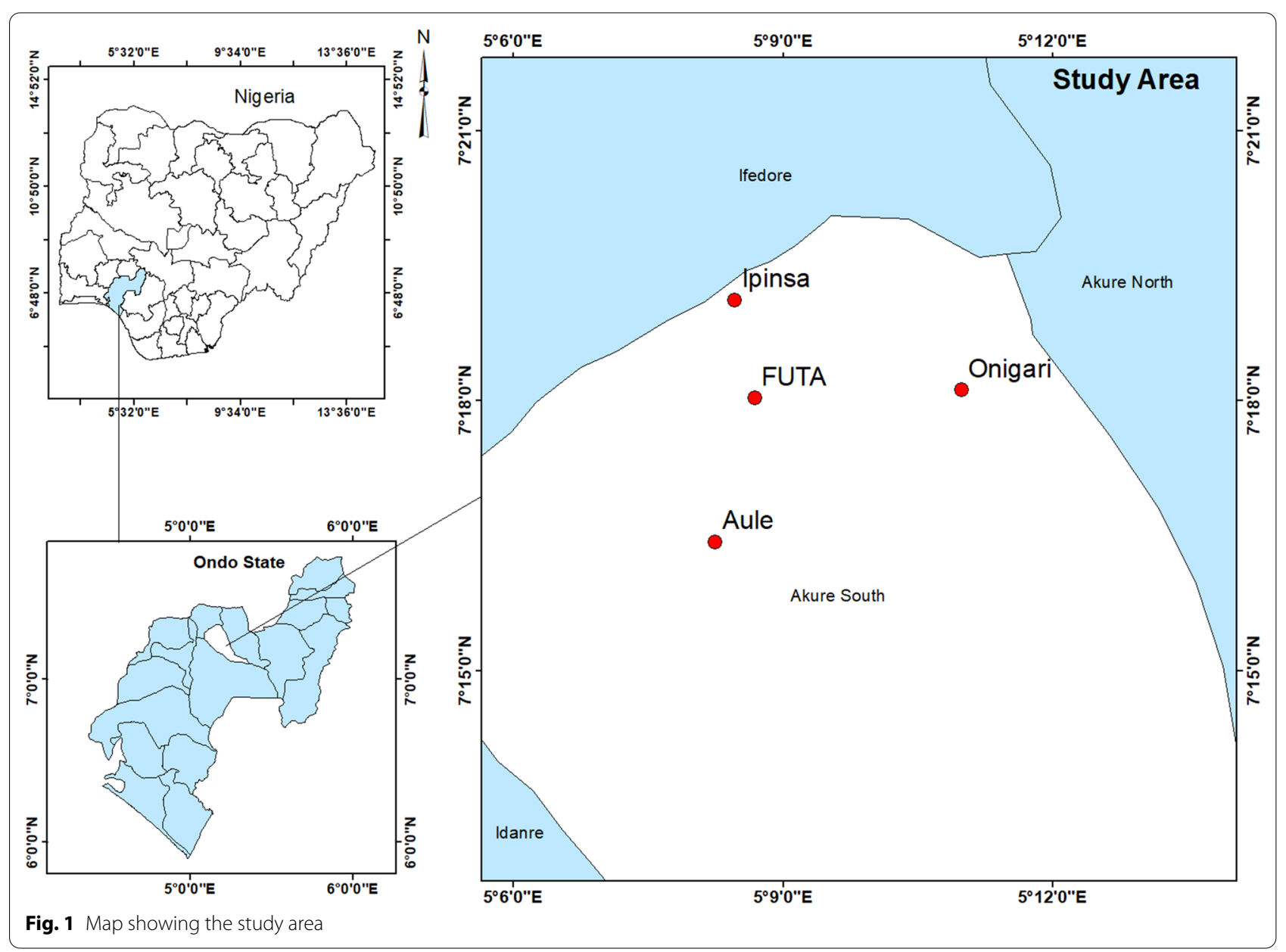


Table 1 Prevalence of Cryptosporidium oocysts in relation to method of rearing

\begin{tabular}{llllll}
\hline Rearing method & $\begin{array}{l}\text { Number } \\
\text { examined }\end{array}$ & $\begin{array}{l}\text { Number } \\
(\%) \\
\text { infected }\end{array}$ & $\boldsymbol{x}^{\mathbf{2}}$ & $\boldsymbol{d f}$ & $\boldsymbol{P}$ value \\
\hline Poultry & 247 & $27(10.9)$ & 0.508 & 1 & 0.476 \\
Free range & 190 & $25(13.2)$ & & & \\
Total & 437 & $52(11.9)$ & & & \\
\hline
\end{tabular}

Table 2 The prevalence of Cryptosporidium oocysts according to sampling location

\begin{tabular}{lccccc}
\hline Sampling location & $\begin{array}{l}\text { Number } \\
\text { examined }\end{array}$ & $\begin{array}{l}\text { Number } \\
(\%) \\
\text { infected }\end{array}$ & $\boldsymbol{X}^{2}$ & $\boldsymbol{d f}$ & $\boldsymbol{P}$ value \\
\hline Aule & 31 & $5(16.1)$ & 2.044 & 4 & 0.128 \\
Ipinsa & 82 & $10(12.2)$ & & & \\
FUTA & 74 & $6(8.1)$ & & & \\
Onigari & 60 & $6(10)$ & & & \\
Total & 247 & $27(10.9)$ & & & \\
\hline
\end{tabular}

\section{Faecal collection}

The sampling exercise was conducted from October 2020 to April 2021. Chickens in steel cages contained 2-3 birds whose faeces were collected on the tray under the cages were considered as one sample, collected by the use of plastic sample bottle, marked with the poultry farm name, bird species, and collection date while that of free-range birds are collected early morning from birds housing in various homes. The sampling process was conducted to collect the fresh droppings to the best of my ability. Samples were kept in a sampling bottle until they were transported to the laboratory, then stored in the refrigerator at $4{ }^{\circ} \mathrm{C}$ and processed as soon as possible. The samples were transported to the undergraduate research Laboratory where they were processed and examined. After smears were prepared, the remaining samples were preserved in $10 \%$ formalin solution and in $2 \mathrm{ml}$ cryo vials. Samples were preserved by freezing at $-20^{\circ} \mathrm{C}$.

\section{Slide preparation}

Using the applicator stick, about $0.2 \mathrm{~g}$ of faecal sample was emulsified onto the slide to make a thin smear which was dried on a slide warmer at $60^{\circ} \mathrm{C}$ for $5 \mathrm{~min}$. The fixed smear was put on the staining rack (accommodating 12 slides per rack at a time). The smears were flooded with Kinyoun's carbol fuchsin for $1 \mathrm{~min}$ after which they were rinsed in distilled water and drained. The smears were then decolourized in $1 \%$ acid-alcohol for $2 \mathrm{~min}$ after which they were washed again with distilled water and counterstained with methylene blue for $2 \mathrm{~min}$. Lastly, the smears were washed with distilled water and drained before drying them on slide warmer at $60{ }^{\circ} \mathrm{C}$ for about $5 \mathrm{~min}$. The stained slides were examined under the microscope using oil immersion objectives ( $\times 100$ objectives) (Sunnotel et al. 2006).

\section{Microscopy detection}

Samples of Cryptosporidium oocysts were examined by optical microscopy observation under $\times 40$ objective then with $\times 100$ oil immersion magnification based on the shape of oocysts and the shape index measured. Oocysts seen were identified with the aid of an atlas encyclopedia of parasitology photographs and manual of parasitology (Bowman 2009).

\section{Data analysis}

Data were entered in Microsoft Excel ${ }^{\circledR}$ spreadsheet and analysed using Statistical Package for the Social Sciences (SPSS) version 16. Proportions of positives, with $95 \%$ confidence intervals, were estimated. The relationships between the presence of Cryptosporidium and hypothesized risk factors were investigated using Chi-square or Fisher's exact test in univariate analyses where appropriate. Results were presented in percentages/proportions, and the multiple effects of predictor variables were investigated using the logistic regression. A significance level of $5 \%$ was used for all tests.

\section{Results}

A total of 437 samples were examined for Cryptosporidium oocysts. Two hundred and forty-seven (247) samples were examined in poultry birds, and one hundred and ninety (190) sample were examined in free range birds. Table 1 showed that out 247 poultry birds' sample, twenty-seven (27) were positive for Cryptosporidium oocysts with prevalence of $10.9 \%$, while out of the 190 samples examined, twenty-five (25) were positive for Cryptosporidium oocysts with prevalence of $13.2 \%$. Generally, a total number of fifty-two (52) sample were observed to be positive Cryptosporidium oocysts given a total prevalence rate of $11.9 \%$. The prevalence of Cryptosporidium oocysts was higher in free range bird's sample (13.2\%) than in poultry bird's sample (10.9\%). Chi-square analysis of data showed that there was no significant difference in the prevalence of Cryptosporidium oocysts observed among samples collected among Poultry and Free-range birds $\left(x^{2}=0.508 ; p=0.476, p>0.05\right)$.

Table 2 showed that out of the thirty-one (31) sample examined from Aule, five (5) were positive for Cryptosporidium oocysts with prevalence of $16.1 \%$ while out the eighty-two (82) sample collected in ipinsa, 10 were positive Cryptosporidium oocysts with prevalence of $12.2 \%$. Seventy-four (74) samples were examined from Futa, and 
six (6) of them were positive for Cryptosporidium oocysts given a prevalence of $8.1 \%$. From the sixty (60) samples collected from Onigari, six (6) were positive for Cryptosporidium oocysts with prevalence of $10 \%$. Chi-square analysis of data showed that there was no significant difference in the prevalence of Cryptosporidium oocysts observed among samples collected in the different sites. $\left(x^{2}=2.044 ; p=0.128, p>0.05\right)$.

Result presented in Table 3 showed that 18 out of the 113 Broilers examined were infected with Cryptosporidium oocysts with prevalence of $15.9 \%, 9$ out of the 100 Layers birds examined were seen to be infected with Cryptosporidium oocysts given a prevalence of $9 \%$, while none of the 34 sample examined from turkey birds were positive to the presence of Cryptosporidium oocysts given it a zero (0\%) prevalence. Of the ninety-five (95) cockerel examined, 15 were positive to Cryptosporidium oocysts with a prevalence of $15.8 \%$. Ninety-five (95) Hen species were examined of which 10 were positive to Cryptosporidium oocysts with a prevalence of $10.5 \%$. Chi-square analysis of data showed that there was no significant difference in the prevalence of Cryptosporidium oocysts observed among bird's species $\left(\chi^{2}=6.377\right.$; $p=0.173, p>0.05$ ).

Prevalence of Cryptosporidium oocysts in relation to System of Bird Farming is presented in Table 4. From the 190 samples collected from semi-intensive system of bird farming, 25 were positive to Cryptosporidium oocysts given a prevalence of $13.2 \%$. 11 out the 107 sample examined from battery cage system were positive to Cryptosporidium oocysts infection leaving the prevalence at $10.3 \%$. In deep litter system of bird farming, 16 were positive from the 127 samples examined given a $12.6 \%$ prevalence. Chi-square analysis of data showed that there was no significant difference in the prevalence of Cryptosporidium oocysts observed among the system of bird farming $\left(\chi^{2}=2.017 ; p=0.365\right.$, $p>0.05)$.

The prevalence of Cryptosporidium between males and female birds is presented in Fig. 2. The Modified

Table 3 The prevalence of Cryptosporidium oocysts according to species of bird

\begin{tabular}{llclll}
\hline Birds species & $\begin{array}{l}\text { Number } \\
\text { examined }\end{array}$ & $\begin{array}{l}\text { Number (\%) } \\
\text { infected }\end{array}$ & $\boldsymbol{x}^{\mathbf{2}}$ & $\boldsymbol{d f}$ & $\boldsymbol{P}$ value \\
\hline Broiler & 113 & $18(15.9)$ & 6.377 & 4 & 0.173 \\
Layer & 100 & $9(9)$ & & & \\
Turkey & 34 & $0(0)$ & & & \\
Cock & 95 & $15(15.8)$ & & & \\
Hen & 95 & $10(10.5)$ & & & \\
Total & 437 & $52(11.9)$ & & & \\
\hline
\end{tabular}

Table 4 The prevalence of Cryptosporidium oocysts according to system of bird farming

\begin{tabular}{llllll}
\hline System & $\begin{array}{l}\text { Number } \\
\text { examined }\end{array}$ & $\begin{array}{l}\text { Number } \\
\text { infected (\%) }\end{array}$ & $\boldsymbol{X}^{\mathbf{2}}$ & $\boldsymbol{d f}$ & $\boldsymbol{P}$ value \\
\hline Battery cage & 107 & $11(10.3)$ & 2.017 & 2 & 0.365 \\
Deep litter & 127 & $16(12.6)$ & & & \\
Semi-Intensive & 190 & $25(13.3)$ & & & \\
Total & 437 & $52(11.9)$ & & & \\
\hline
\end{tabular}

Ziehl Neelsen method detected 25 (11.6\%) positive samples in males, slightly lower than the $12.2 \%(27 / 222)$ detected in female birds. The prevalence of Cryptosporidium between males and females' birds was not significant different $(p=0.863, p>0.05)$.

\section{Discussion}

The prevalence of Cryptosporidium species in both poultry and free-range birds in Akure South Local Government of Ondo State, Nigeria was determined in this study. Other studies have previously confirmed the presence of Cryptosporidium species in birds with variations in prevalence from place to place, which could be due to climatic, breed, sex, and the bird farm management differences used. The overall prevalence of Cryptosporidium infection reported in this current study was $11.9 \%$ which was higher than that recorded in Tunisia (4.5\%) by Soltane et al. (2007), 5.1\% reported in Germany according to Helmy et al. (2017), 7.4\% prevalence result of Bamaiyi et al. (2013) in Zaria, Nigeria, and 8.1\% publication by Meng et al. (2011) in China, previous studies use both diagnostic approach of microscopic examination and molecular genotyping. However, slightly lower to the $14.8 \%$ in Brazil by Da Cunha et al. (2018) and $19.8 \%$ in Bangladesh by Kabir et al. (2020). The difference in the prevalence rates may be attributed to the use of different detection methods (histology, serology, and microscopy), management system, farm control practice, and seasonal difference in the study areas.

\section{The prevalence of Cryptosporidium oocysts according to rearing method}

Free-range birds show a higher prevalence rate $13.2 \%$ of Cryptosporidium oocysts than poultry birds, and this was in agreement with the findings of Bamaiyi et al. (2013) in Zaria, Nigeria. This higher infection rate may be attributed to the fact that free-range birds are allowed to roam about freely thereby exposing them to multiple sources of infection through sporulated oocysts from water, livestock, and human during feeding (Ryan 2010) compared to the exotics poultry bird which are kept in cage and confide 


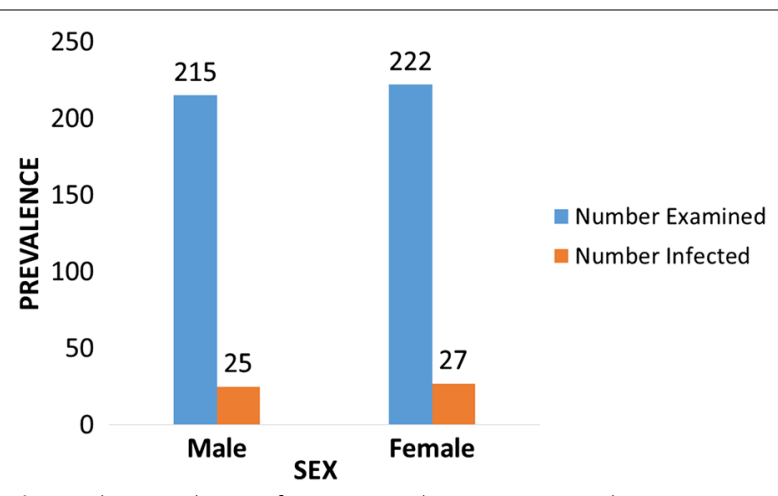

Fig. 2 The Prevalence of Cryptosporidium oocysts in relation to Sex

compartment that restrict wide range of roaming about. Furthermore, it could be as a result of accumulation of the parasite from smaller intermediate host like cockroaches which have been confirmed to be positive to Cryptosporidium during feeding compared to the poultry birds which are fed with processed feeds (Kumar et al. 2014).

\section{The prevalence of Cryptosporidium oocysts according to sampling location}

The present study reveals that irrespective of the site, birds are all susceptible to Cryptosporidium infection. Cryptosporidium oocysts prevalence was higher at Aule and Ipinsa with $16.1 \%$ and $12.2 \%$ prevalence, respectively, than every other location, in my personal observations this may be as a result of various favourable factors that support the infection of Cryptosporidium to thrive in Aule and Ipinsa farm which may include poor hygiene, farm management where deep liter system of farm management which can encourage oocysts survival and increase the viability (Gascon et al. 2000).

\section{The Prevalence of Cryptosporidium oocysts according to species of bird}

The prevalence rate of Cryptosporidium oocysts varies between different bird species examined. The higher prevalence was recorded in broilers birds in this study than their cock, layers, and hen counterpart, and this finding was in contrast with the work of Wang et al. (2010) and Helmy et al. (2017). However, was in agreement with the report of Kabir et al. (2020) where they recorded a higher prevalence in broiler than in layer chicken. This is also in agreement with reports by Nnadi and George (2010) in Southeastern, Nigeria; Nematollahi et al. (2009) in Iran; Jatau et al. (2012) in Zaria, Northwestern Nigeria and Naphade, 2013 in India. This might be connected with higher stocking densities and intensive husbandry management systems practiced in broiler production in the study area.

\section{The prevalence of Cryptosporidium oocysts according} to system of bird farming

Semi-intensive system of farming was showed to be more susceptible to Cryptosporidium oocysts infection, and this may be attributed to the fact that the birds will have access to more sources of Cryptosporidium oocysts as they roam about and feed on soil content, livestock faeces, and other vector that habour C. oocysts (Ryan 2010). The result of this study also revealed that from the intensively managed poultry farm with deep litter system and constructed battery cage, the prevalence was relatively higher in the deep litter system than the battery cage management system. This was in agreement with the finding of Lawal et al. (2016) which can be attributed to sporulation of buildup oocysts resulting from spillage of water and humid environment which lead to relatively high oocysts accumulation according to the report of Dakpogan and Salifou (2013) and Taylor et al. (2007) as most of the farms with deep litter left the floor dust for more than a week before replacement. The Battery Cage system of farming was showed to have the least prevalence, and this may be as a result of the iron cage structure use to house the birds as birds do not have access to pick infected faeces because they drop direct under the cage as the cage are raised above the ground level in the study area.

\section{The prevalence of Cryptosporidium oocysts according to sex}

The finding from this present study is in agreement with the work of Bamaiyi et al. (2013) that acclaimed that both sex of birds is susceptible to Cryptosporidium oocysts infection. The prevalence of Cryptosporidium oocysts was higher in female birds than in male birds, and this may be attributed to the high susceptibility of female to infection due to reduced immunity at certain period of reproductive cycle as reported by Gbemisola et al. (2016). This also indicated that females were more likely to contract intestinal protozoa than male (Davoust et al. 2008). However, this was in contrast to the findings of Zhang et al. (2015) in a work done in North china. The prevalence indicates that both sexes have equal chance of becoming infected with Cryptosporidium oocysts during feeding and outbreak of infection (Oljira et al. 2012).

\section{Conclusions}

Although the identification of Cryptosporidium species was not decided in this study but most of the sample observed morphological resemble C. baileyi which is probably the most common avian Cryptosporidium species. The results of the present study established the presence of Cryptosporidium infection among birds surveyed in Akure South LG of Ondo State Nigeria. The overall 
prevalence of Cryptosporidium reported in the study was $11.9 \%$, and it also revealed that all species of birds, sex of birds, and system of bird's management are susceptible to Cryptosporidium sp. infection which can act as a source of human Cryptosporidiosis. Poor management practice is the main risk factor favouring the onset of Cryptosporidium such as oocysts build-up, oocysts sporulation, and the humid environment.

\section{Acknowledgements}

The authors appreciate the Chief Laboratory Technologist of the Department of Biology, Federal University of Technology, Akure for her support. We appreciate the support of Babatunde Olugbenga and Akeju Adebayo for their assistance during data collection.

\section{Authors' contributions}

OAA and OTA contributed to the research design and involved in field and laboratory work. OAA carried out statistical analysis and interpret the result of the study. OAA write the first draft of the manuscript. OTA review the manuscript. All author read and approved the final manuscript.

\section{Funding}

This research work did not receive external funding.

\section{Available of data and materials}

All analysed data involved in this study are included in this manuscript.

\section{Declarations}

\section{Ethics approval and consent to participate}

Not applicable.

\section{Consent for publication}

Not applicable.

\section{Competing for interests}

The authors declare that they have no competing interests.

Received: 5 August 2021 Accepted: 28 September 2021

Published online: 19 October 2021

\section{References}

Bamaiyi PH, Umoh JU, Abdu PA, Lawal IA (2013) The Prevalence of Cryptosporidium oocysts in Birds in Zaria, Nigeria. Borneo J Resour Sci Technol 2(2):52-59

Bialek AJ, Ives NJ, Gazzard BG, Easterbrook PJ (2002) the changing pattern of AIDS defining illness with the introduction of (HAART) in a London clinic. J Infect 42:134-139

Bowman DD (2009) Georgis' parasitology for veterinarians, 9th edn. Elsevier, Amsterdam, pp 479-89

Da Cunha MR, Cury MC, Santi M (2018) Molecular characterization of Cryptosporidium spp in Poultry from Brazil. Res Vet Sci 118:331-35

Dakpogan HB, Salifou S (2013) Coccidiosis prevalence and intensity in litter based high stocking density layer rearing system of Benin. J Anim Plant Sci 17(2):2522-2526

Davoust B, Normand T, Bourry O, Dang H, Leroy E, Bourdoiseau G (2008) Epidemiological survey on gastrointestinal and blood-borne helminths of dogs in north east Gabon. J Vet Res 75:359-364

DuPont HL, Chappell CL, Sterling CR, Okhuysen PC, Rose JB, Jakubowski W (1995) The infectivity of Cryptosporidium parvumin healthy volunteers. N Engl J Med 332:855-859

Fayer R (2010) Taxonomy and species delimitation in Cryptosporidium. Exp Parasitol 124:90-97

Fayer R, Morgan U, Upton SJ (2000) Epidemiology of Cryptosporidium: transmission, detection and identification. Int J Parasitol 30:1305-1322

Gascon J, Vargas M, Schellenberg D, Urassa H, Casals C, Khaigwa E, Appointe $\mathrm{J}$, Mashinda H, Villa J (2000) Diarrahoea in children under 5 years old of age from Ifakara, Tanzania, a case control study. J Clin Microbiol 38(12):4459-4462

Gbemisola MO, Beatty VM, Gbeminiyi RO (2016) Prevalence and risk factors associated with faecal shedding of Cryptosporidium oocysts in dogs in the federal capital territory, Abuja, Nigeria. Vet Med Int 4591238:1-6

Harp JA (2003) Parasitic infections of the gastrointestinal tract. Curr Opin Gastroenterol 19:31-36

Helmy YA, Kricken J, Abdelwhab ESM, Samson-Himmelstjerna G, Hafez HM (2017) Molecular diagnosis and characterization of Cryptosporidium spp. in turkeys and chickens in Germany reveals evidence for previously undetected parasite species

Jatau ID, Sulaiman NH, Musa IW, Lawal Al, Okubanjo Isah OO, Magaji Y (2012) Prevalence of Coccidia infection and preponderance Eimeria species in free range indigenous and intensively managed exotic chickens during hot-wet season, in Zaria, Nigeria. Asian J Poult Sci 6:79-88

Kabir MH, Han YS, Leea S, Nugrahaa AB, Recuenco F, Murakoshi F, Xuana X, Kato K (2020) Prevalence and molecular characterization of Cryptosporidium species in poultry in Bangladesh. One Health 9:100122

Khan WA, Rogers KA, Karin MM, Ahmed S, Hibberd PL, Calderwood SB (2004) Cryptosporidiosis among Bangladeshi children with diarrhoea: a prospective, matched, case control study of clinical features, epidemiology and systemic antibody responses. Am J Trop Med Hyg 71:412-419

Kjos SA, Jenkins M, Okhuysen PC, Chappell CL (2005) Evaluation of recombinant oocyst protein CP41 for detection of Cryptosporidium-specific antibodies. Clin Diagn Lab Immunol 12:268-272

Kumar S, Garg R, Moftah A, Clark EL, Macdonald SE, Chandhury AS, Sparagano O, Benerjee PS, Kuudu K, Tomley FM, Blake DP (2014) An optimized protocol for molecular identification of Eimeria for Chicken. Vet Parasitol 199:24-31

Lawal JR, Jajere SM, Ibrahim UI, Geidam YA, Gulani IA, Musa G, Ibekwe BU (2016) Prevalence of coccidiosis among village and exotic breed of chickens in Maiduguri, Nigeria. Vet World 9(6):653-659

LeChevallier MW, Norton WD, Lee RG (1991) Giardia and Cryptosporidium spp. in filtered drinking water supplies. Appl Environ Microbiol 57:2617-2621

Meng Q, Wang R, Ning C, Li X, Zhang L, Jian F, Sun Y, Xiao L (2011) Cryptosporidium spp. in pet birds: genetic diversity and potential public health significance. Exp Parasitol 128:336-340

Nematollahi A, Gholamali M, Reze FP (2009) Prevalence of Eimeria species among broiler chicks in Tabriz, Iran. Munis Entomol Zool J 4:53-58

Nnadi PA, George SO (2010) A cross-sectional survey on parasites of chickens in selected villages in the sub humid zones of South-Eastern Nigeria. J Parasitol Res 141:1-6

Oljira D, Melaku A, Bogale B (2012) Prevalence and risk factors of coccidiosis in poultry farms in and around Ambo Town, Western Ethiopia. Am Eurasian J Sci Res 7(4):146-149

Ryan U (2010) Cryptosporidium in Birds, Fish and Amphibians. Exp Parasitol 124(1):113-120

Savioli L, Smith H, Thompson A (2006) Giardia and Cryptosporidium join the 'neglected diseases initiative.'Trends in Parasitology 22:203-208

Soltane R, Guyot K, Dei-Cas E, Ayadi A (2007) Prevalence of Cryptosporidium spp. (Eucoccidiorida: Cryptosporiidae) in seven species of farm animals in Tunisia. Parasite 14:335-338

Sunnotel O, Snelling WJ, Xiao L, Moore P, Millar BC, Dooley JSG, Lowery CJ (2006) Rapid and sensitive detection of single Cryptosporidium oocysts from archieved glass slide. J Clin Microbiol 44(9):3285-3291

Taylor MA, Coop RL, Wall RL (2007) Parasite of poultry and game birds. In: Anderson JM, Macfadyen A (eds) Veterinary parasitology. Blackwell Publishing, lowa State, pp 459-557

Wang R, Jian F, Sun Y, Hu Q, Zhu J, Wang F, Ning C, Zhang L, Xiao L (2010) Largescale survey of Cryptosporidium spp in chickens and Pekin ducks (Anas platyrhynchos) in Henan, China: prevalence and molecular characterization. Avian Pathol 39(6):447-451

Zhang XX, Zhang NZ, Zhao GH, Zhao Q, Zhu XQ (2015) Prevalence and Genotyping of Cryptosporidium Infection in Pet Parrots in North China. Hindawi Publ Corp BioMed Res Int 549798:6

\section{Publisher's Note}

Springer Nature remains neutral with regard to jurisdictional claims in published maps and institutional affiliations. 